Review Article

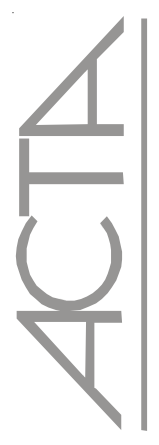

\title{
Aging, Diversity, and Health: the Brazilian and the Canadian context
}

\author{
Envelhecimento, Diversidade e Saúde: contexto brasileiro e canadense \\ Envejecimiento, Diversidad y Salud: contexto brasileño y canadiense
}

\begin{abstract}
Aging is a universal and yet diverse phenomenon. This paper presents a review on the topic of diversity in the context of the aging populations in Brazil and Canada. The diversity of the aging population in both countries is discussed in terms of gender, ethnicity, age groups and living conditions while considering the impact on the health care systems. Understanding and reflecting on the Brazilian and Canadian realities reinforces the need for respecting these diversities when developing and implementing local health policies and interventions. There are some similarities regarding gender, but marked differences in immigration patterns, education and living arrangements. The beterogeneity in the aging process within each country and between them carries different expectations and generates social consequences that manifest themselves in differences in health situations, resulting in new challenges to health services and the formulation of public policies for this age group in both countries.
\end{abstract}

Lisiane Manganelli Girardi Paskulin ${ }^{1}$, Marinês Aires², Ana Valéria Goncalves ${ }^{3}$, Carla Cristiane Becker Kottwitz ${ }^{4}$, Eliane Pinheiro de Morais 5 , Mario Augusto Brondani $^{6}$

Keywords: Cultural diversity; Demographic aging; Elderly; Health Care (Public health); Cross-cultural comparison

\section{RESUMO}

O envelhecimento é um fenômeno universal e ainda diverso. Este estudo apresenta uma revisão sobre a diversidade no contexto do envelhecimento populacional no Brasil e Canadá. Esta diversidade em ambos os países é discutida em termos de gênero, etnia, faixa etária e condições de vida ao considerar o impacto aos sistemas de saúde. Entender e refletir sobre as realidades brasileira e canadense reforça a necessidade de respeitar essas diversidades no desenvolvimento e implementação de políticas locais de saúde e de intervenções em saúde. Existem algumas semelhanças em relação ao gênero, mas destacam-se diferenças nos padrões de imigração, educação e arranjos domiciliares. A heterogeneidade no processo de envelhecimento de cada país e, entre eles, envolve diferentes expectativas e gera consequências sociais que se manifestam em distintas situações de saúde, resultando em novos desafios aos serviços de saúde e na formulação de políticas públicas para esse grupo etário em ambos os países.

Descritores: Diversidade cultural; Envelhecimento da população; Idoso; Atenção à saúde; Comparação transcultural

\section{RESUMEN}

El envejecimiento es un fenómeno universal y aun diverso. En este estudio se presenta una revisión sobre la diversidad en el contexto del envejecimiento poblacional en el Brasil y Canadá. Esta diversidad en ambos países es discutida en términos de género, etnia, grupo etáreo y condiciones de vida al considerar el impacto para los sistemas de salud. Entender y reflexionar sobre las realidades brasileña y canadiense refuerza la necesidad de respetar esas diversidades en el desarrollo e implementación de políticas locales de salud y de intervenciones en salud. Existen algunas semejanzas en relación al género, sin embargo se destacan diferencias en los patrones de inmigración, educación y arreglos domiciliarios. La heterogeneidad en el proceso de envejecimiento de cada país y, entre ellos, involucra diferentes expectativas y genera consecuencias sociales que se manifiestan en distintas situaciones de salud, resultando en nuevos desafíos para los servicios de salud y en la formulación de políticas públicas para ese grupo etáreo, en ambos países.

Descriptores: Diversidad cultural; Envejecimiento de la población; Anciano;Atención a la salud; Comparación transcultural

${ }^{1}$ PhD in Health Sciences. Professor at the Nursing Graduation Program (NGP), Universidade Federal do Rio Grande do Sul - UFRGS - Porto Alegre (RS), Brazil.

2 Master in Nursing. Faculty member of the Universidade Regional Integrada do Alto Uruguai e das Missões - URI - Frederico Westphalen (RS), Brazil

${ }^{3}$ Master's Student in Nursing by Nursing Graduation Program (NGP), Universidade Federl do Rio Grande do Sul - UFRGS - Porto Alegre (RS), Brazil.

${ }^{4}$ Undergraduate student in Nursing at the Nursng School, Universidade Federl do Rio Grande do Sul - UFRGS - Porto Alegre (RS), Brazil.

${ }^{5}$ PhD in Fundamental Nursing. Associate Professor of Nursing Graduation Program (NGP), Nursing School, Universidade Federal do Rio Grande do Sul - UFRGS- Porto Alegre (RS), Brazil.

${ }^{6}$ Dentist. PhD in Dental Sciences. Assistant Professor at the Undergraduate and Graduate Programs at the University of British Columbia Faculty of Dentistry, Vancouver, BC, Canada.

Autor Correspondente: Marinês Aires

Artigo recebido em 26/01/2011 e aprovado em 15/06/2011

R. Comércio, 724 - Centro - RS - Brasil

Cep: 94000-000 E-mail: marynesayres@yahoo.com.br 


\section{INTRODUCTION}

During the winter of 2008, a collaborative online course on aging and diversity took place at the Nursing Graduate Program, Federal University of Rio Grande do Sul, Brazil. The course Aging, health and diversity: the Brazilian and the Canadian contexts was taught simultaneously by the first and last authors under the bilateral agreement between the UBC Faculty of Dentistry and the UFRGS Faculty of Nursing and from the Canadian Studies Faculty Enrichment Program provided by the Canadian Government - Department of Foreign Affairs and International Trade - through a scholarship awarded to the first author. The goal was to analyze aspects related to the diversity of the aging process in both countries and its implications for health care. This paper reflects a group of students' (the second and third authors) review project on the topic of aging and diversity in the context of Brazil and Canada.

Aging is a universal and diverse phenomenon. Although life expectancy is higher in North America, Europe and Japan, the absolute number of older adults is concentrated in developing countries including India, China, and South American nations ${ }^{(1)}$. As a developing country, Brazil has experienced rapid growth in its aging population, particularly for the past 50 years, that has not been accompanied closely by corresponding socio-economic growth and health care improvement. As a result, these Brazilian older adults have experienced aging within social and economic inequalities ${ }^{(2)}$. On the contrary, Canada, similar to most developed nations, has experienced a gradual increase in its elderly population that has been followed closely by an improvement in socioeconomic conditions. As the Canadian aging process is somewhat longer but more gradual, older Canadian adults have been more able to maintain the basic aspects of life they achieved during their younger years. Such differences in the aging process are also reflected in the cut-off chronological age in which a person is considered older: $60 \mathrm{yrs}$ in Brazil and 65 in $\mathrm{Canada}^{(3)}$. These dissimilarities became relevant for planning social programs and health care delivery in the two different contexts and for examining socioeconomic and cultural conditions experienced by the elderly populations of these two countries.

Brazil, the fifth largest country in the world, had $190,732,694$ inhabitants in 2010,10.77\% being older than $60 \mathrm{yrs}^{(4)}$. During the $1940 \mathrm{~s}$, $5 \%$ of the total population was 60 years old and older whereas in 2000 , this percentage increased to $8.6 \%$. Projections for 2050 indicate that almost $30 \%$ of the Brazilian population will be 60 years and older, placing Brazil as one of the countries with the largest absolute number of elderly people worldwide ${ }^{(5)}$.

Canada, having the second largest land mass in the world for a single country, had an estimated population of 33.5 million in 2008, almost one sixth of the Brazilian population, and less than the state of Sao Paulo alone, which had a population of 41 million in 2010 . In the 1920 s about $5 \%$ of the Canadian population was older than 65 years whereas in 2008 , the percentage jumped to $13.8 \%{ }^{(6-7)}$. Projections for 2050 show that $40 \%$ of the Canadian population will be older than 65 yrs, or expressed another way, there will be two seniors per each child under the age of 5 yearsold $^{(7)}$. Within the elderly population, the proportion of the "very old", considered to be 80 years and older in Brazil and 85 years and older in Canada, is increasing at unprecedented rates. During the 1940 s, $10 \%$ of the elderly Brazilian population was composed of the very old and by the 2000 s this percentage had increased to $13 \%{ }^{(8)}$. Canada experienced a more dramatic increase of those older than the age of 85 , from less than $1 \%$ in the 1950 s to $1.5 \%$ in 2005 . With the "baby boomers" reaching this age between 2021 and 2056, the Canadian 'very old' will become almost $20 \%$ of the aging population ${ }^{(7)}$.

Such uniqueness emphasizes the need to understand the aging process within the diversity of the populations in which it occurs. Diversity is a concept used in different disciplines and can be understood within groups as well as within the structural social and political positions individuals hold in society. Diversity encompasses acceptance and respect ensuring the preservation of the individuals' self ${ }^{(9)}$. In this meaning, diversity can also be related to inequalities or inequities, particularly in terms of access to care, workforce, social and psychological well-being, and education, for example, when different groups have their diverse needs unmet ${ }^{(10)}$. Several characteristics make an older person different or may cause them to experience discrimination, including gender, ethnicity, culture, housing, education level, marital status, living arrangements, sexual orientation, and religion.

Societies in general are getting more diverse and more diversity issues will be experienced in the future, but will not necessarily be taken into consideration when planning for and delivering nursing care and health services to this population in areas ranging from basic needs, home care, long-term care facilities and complex patient management.

Within a diverse environment, 'minority' groups require society to be more sensitive to their voices. Unless we understand the dynamics of diversity, it is hard to understand the social and political consequences of oppression, of conflict or the advantages and disadvantages in aging present within the experiences of those from different groups ${ }^{(11)}$.

The goal of this paper is to review the aging process experienced in Brazil and in Canada while considering some aspects of diversity, including living arrangements, immigration patterns, gender identity and sexual orientation, education, and the impact of all these on the health care system. To this end, a narrative review of the literature was undertaken in $2010^{(12)}$. We draw from the relevant papers published between 1999 and 2009 that were available at Scielo database and that matched the descriptors "elderly" or "elderly health" with "population ageing" as papers from PubMed database with the Mesh Terms: "first nations/indigenous and aged", "homosexuality and aged". We have also accessed book chapters and reports on population data, existing policies, and regulations as they pertain to older adults in both countries. 
There is a limited number of studies about social determinants of health or diversity for older adults and even fewer studies that are cross-cultural. It is well known that health is a socially mediated process ${ }^{(13)}$ and hence it is important that nurses and other health professionals are aware of diversity issues.

DIVERSITIES AND SIMILARITIES ON THE AGING PROCESS IN CANADA AND BRAZIL AND THE IMPLICATIONS TO HEALTH CARE

In order to better understand the similarities and differences between the aging process in both countries and the corresponding implications to health care, it is important to situate some characteristics of the health care systems in terms of the socioeconomic and health conditions of each country.

Considering health care systems, Canada has the largest socialized health insurance in the world via the Canada Health Act that established Medicare in 1984 that includes all its pernanent redidents and cizens. Medicare constitutes the national system of health care governed by the principles of universality, portability, accessibility, inclusion and public administration. It is shared between the federal government and the provinces. The financing of the health sector is by taxation, in the form of individual income and business taxes ${ }^{(14)}$. Brazil has a National Health System (SUS) provided by federal, state and local governments, and regulated by the Federal Constitution in 1988. Health is considered a right and a duty of the State. Similarly to Medicare, the SUS principles' are universality, comprehensiveness, equity, decentralization of health care and popular participation.

It is also important to highlight some of the general socioeconomic and health conditions found in both countries. Life expectancy in Canada in 2007 was 83 years for women and 78 for men and the average monthly income per capita of the family of an older person was around $\$ 3,000$ in $2003^{(6-7)}$. The same family in Brazil had an average income of $\$ 100$ per month ${ }^{(5)}$ and life expectancy was 73.1 years at birth in $2010^{(4)}$. But Canada and Brazil share some similarities, including the main causes of death in old age: cardiovascular, cancer and respiratory diseases ${ }^{(15-16)}$ although external causes are also a major cause of death in Brazil.

We now present and discuss some aspects of diversity including ethnicity, gender, living arrangements and education and the impact of all these on the health care system.

One of the features of Canadian society, different from Brazil, is its openness to immigrants and to ethnocultural diversity. According to Statistics Canada ${ }^{(7)}$, the majority of Canadian seniors are first generation immigrants with English or French as their second language; less than $4 \%$ of new immigrants were older adults themselves ${ }^{(17)}$. There is great diversity of ethnic groups including French, Scottish, Irish, Germans, Italians, Greeks, Eastern Europeans, and also Chinese and South East Asians, two of the largest visible minorities. Compared to Canada, Brazil experienced a similar trend during the post-war period but now receives very few immigrants. However, Brazil does contribute to the immigration influx of countries such as Canada, the US and Australia. As a result, Brazil tends to encompass a 'melting pot' of cultures that try to blend in whereas Canada is seen more as a 'mosaic', with some differentiation and respect of different cultures. Such a Canadian mosaic may impact health care delivery and access to it since issues specific to language, cultural values and beliefs, food preference and personal habits have to be considered, particularly for older adults living in long-term care facilities.

Another aspect of diversity that occurs in both Canada and Brazil relates to First Nations communities. The Brazilian indigenous population registered in 2008 was composed predominantly of young individuals under the age of 20. People older than 50 years were not more than $5 \%$ of the total indigenous population. Stigma, lack of land and shelter, and discrimination are the main adversities faced by this segment of the Brazilian population, which still suffers from infectious diseases and lack of health care ${ }^{(18)}$. The Canadian Aboriginal population accounted for 3.3\% of Canada's total population in 2006; $3 \%$ were individuals older than 65 years ${ }^{(17)}$. Stigma, lack of land and shelter, and discrimination are also experienced by the Canadian First Nations, and they do present with higher suicide rates, alcoholism, diabetes and cardiovascular disease mostly due to unmet social needs and a dramatic change in life style compared with their past including adoption of a modern diet. In both countries, the life expectancy of any aboriginal age group is shorter than that of the general population. Elderly aboriginal people in particular are more likely to have less education, to be widowed and to live in large households than the general Canadian population ${ }^{(15,19-20)}$. One of the challenges to be overcome by both countries is the appropriateness of health services to the specific needs of their indigenous populations, respecting the principles of universality, portability, accessibility, inclusion and equity.

Another area of diversity concerns gender in two aspects, gender as the absolute number of men and women and gender as related to sexual orientation. The feminization of old age occurs because more women than men reach older ages, and women are expected to live 10 years longer than men. The Portrait of Seniors in Canada states that one of the important advances yet to be made is to reduce the difference in life expectancy between men and women ${ }^{(7)}$. In Canada in the year 2008, women made up $52 \%$ of those between the ages of 65 and 69 years and $75 \%$ of those older than 90 years ${ }^{(17)}$. In Brazil, according to the latest population Census of $2010,55.53 \%$ of the elderly population were women ${ }^{(4)}$. The higher life expectancy of women worldwide may be explained by biological, genetic and social factors combined with the fact that more female elderly adopt healthy behaviors in terms of lower consumption of alcoholic beverages and tobacco ${ }^{(15)}$. Although women live longer than men, they are more vulnerable, tend to be poorer, receive lower wages, and 
live alone after widowhood whereas men, when remarrying, choose younger women. These occurrences are observed both in Brazil ${ }^{(21)}$ and in Canada ${ }^{(15)}$. Thus, gender is an element of both diversity and inequality and generates demands for sensitive health care at all its levels. In terms of social support, older women in Canada tend to have a more 'formal' support network whereas in Brazil, support is given primarily through the family. Although the elderly tend to form the largest age group accessing the health care system, the focus is still on curative procedures in Brazil whereas the focus is somewhat more preventive in Canada.

When gender is discussed in terms of sexual orientation, Canada more often than Brazil is viewed as a welcoming nation embracing ethno-cultural values and diversity. As a matter of fact, in July 20, 2005, Canada became the fourth country in the world and the first country in the Americas to legalize same-sex marriage even though most legal benefits associated with same-sex marriage had been in place since 1999. But all these achievements in diversity might not be as transparent and positive as they look, and exclusion may still occur. For example, the Canadian health system and social services offer resources for seniors in general, but seniors who are lesbian, gay, bisexual, or transsexual can be doubly marginalized and they may have their needs overlooked by the health care system and their own gay community ${ }^{(22)}$. Seniors over 70 today grew up before gay liberation as homosexuality was decriminalized in Canada only in $1969^{(23)}$. As a result, they may have a tendency to be more private about their sexuality (and deny their identity when feeling unsafe to disclose) to the extent that the estimation of $5-10 \%$ of the senior population self-identifying as LGBT in Canada might be underestimated. Hence, these seniors may be less adamant about demanding LGBTspecific health and social services. This negatively impacts healthy aging and a personal sense of well-being ${ }^{(24)}$. In Brazil, despite the generalized view that its population embraces sexuality, studies on homosexuality are still new and specific studies related to aging are even more scarce. In fact, the few studies that exist deal mainly with attitudes of the general population regarding homosexuality ${ }^{(25)}$, with transexuality in the context of gender identity, gender reassignment, and pathology $\mathrm{y}^{(26)}$.

In general terms, Canada places greater attention to services and support for the elderly through formal home-care, assisted-living homes, and day hospitals while encouraging older adults to remain in their homes. This is not a reality in Brazil which, despite legislation, has home care for frail elderly in the public sector still incipient. When the care exists, it is most often performed by informal caregivers where maintenance of the oldest old within the family becomes increasingly difficult mostly due to unfavorable socioeconomic conditions, changes in family structure and the decline of the extended family. Likewise, Brazil does not have an official support system for informal caregivers whereas Canada may be more generous in some provinces and offer some level of help especially in terms of respite day- care support. Hence, there is some limited financial support for Canadian informal caregivers when they have to stop working at their regular jobs temporarily to take care of an older adult.

In terms of living arrangements, surveys conducted in several Brazilian cities found between $8-21 \%$ of the elderly living alone ${ }^{(27-28)}$ compared to $22-34 \%$ of the same age group in Canada ${ }^{(29)}$. It is noteworthy that there is a greater proportion of the very old living alone in Canada, a situation that does not happen in Brazil. It is possible that these differences account for older Canadians living by themselves while in Brazil they tend to live with family members in most cases. Brazil more than Canada has families depending on the retirement wages of their elders for a household comprised of parents, children, grandchildren and great grandchildren. In terms of urbanization, Brazil has less than $20 \%$ of the elderly living in rural areas ${ }^{(4)}$ a similar situation observed in Canada ${ }^{(7)}$. In both countries, the aging characterization in urban and rural areas tends to be the same, e.g., a predominance of older women, but with further lack of resources and access to health services.

Socio-economic and education status represent another large disparity in Brazil that is not experienced by the majority of older adults in Canada. While $50 \%$ of older Canadians finished high school or more ${ }^{(7)}$ this percentage is less than $20 \%$ in Brazil ${ }^{(5)}$. Although it is well known that a low literacy level has a direct impact on health education and access, the issues of diversity presented above are complex and multifaceted.

These diversities bring about many health inequities in both countries considering the excessive burden of chronic illness, poor health outcomes (as potential years of life lost, more hospitalizations and suicide deaths) and also social exclusion. Nurses and other health professionals can work in many ways to try to reduce these inequities. In primary care it is necessary that nurses have an understanding of the elder persons who reside in the territory in order to develop appropriate programs promoting health and active aging. These programs must be suitable to the reality of each community. When disease has already occurred, the focus turns to education to prevent complications, to assessment of the possibilities for self-care and what must be provided by nurses and other health professionals. Knowing the context of an older person's life and identifying his or her particular needs is also imperative. In addition, it is important to develop actions on a network basis, involving both health and support services to ensure comprehensive health care. As well, nurses can work to facilitate access and equity, thus helping older people who are not aware of the resources available to them. They can also advocate within communities to ask for more services to help older persons stay home alone or with their families and also for more facilities for those who cannot stay at home.

Considering undergraduate and graduate education and also continous education, it is necessary to put greater focus on health promotion and disease prevention, 
builting capacities to understand that different individuals or groups have different positions in society and have different opportunities in health and life and so preparing nurses to address inequities in health and health care.

As a result, no single health perspective provides all the answers or the best solutions to the care of elders. Interdisciplinarity seems to offer the greatest possibility of meeting diverse needs with best practices by engaging health professionals who are trained to work comfortably with each other to care for the aging population accordingly. It is also necessary to include other societal sectors to address diversity to thus enhances policy coherence and facilitate interventions on the determinants of health.

\section{FINAL CONSIDERATIONS}

Considering the aging process in both countries discussed in this paper, there are some some similarities regarding gender, but marked differences in immigration patterns, education and living arrangements. The heterogeneity in the aging process and health care within each country and between them carries different expectations and generates social consequences that manifest themselves in differences in health situations, resulting in new challenges to health services, health professionals and the formulation of public policies for this age group in both countries.

Brazil has specific policies established to ensure the rights of older people. Although Canada has specific national and provincial policies on issues related to older adults, they are not as encompassing as the Brazilian legislation. But this is not necessarily a drawback since it is believed that in Canada the respect for citizens' rights is already ingrained in society and occurs almost naturally. In Brazil, on the contrary, there is a need to develop policies and laws, although these are not always enforced.

Brazil has most of its aging population living in poverty, with low education, a high prevalence of multiple chronic diseases and without formal social support. Although the increase in life expectancy is

\section{REFERÊNCIAS}

1. Holtz C. Global health care: issues and policie. Sudbury (MA): Jones \& Bartlett; 2008.

2. Palloni A, Peláez M. History and nature of the study. In: Lebrão ML, Duarte YA, organizers. KNOW - health wellness and aging: the SABE project in the municipality of São Paulo - an initial approach. Brasília: Pan American Health; 2003. p 15-32.

3. United Nations General Assembly. Resolution n.37/51 3 December 1982. Plan of action on ageing [Internet]. 1982 [cited 2011 Sept 15]. Available from: http://www.un.org/ documents/ga/res/37/a37r051.htm.

4. Instituto Brasileiro de Geografia e Estatística. Search national household sample. Brazil [Internet]. 2010. [cited 2011 May 02]. Available fromt: http://www.ibge.gov.br/ censo2010/primeiros_dados_divulgados/index.php.

5. Beltrão KI, Camarano AA, Kanso S. Brazilian population dynamics at the turn of the century XX. Rio de Janeiro: considered one of the major social achievements of the twentieth century, these conditions characterize Brazil as one of the most unequal countries in terms of socioeconomic and health inequalities. Although there is some expectation of economic growth for Brazil in the next decades, the future of its older adults in terms of health and social series remains a challenge to be addressed at the individual, community and social levels. While the increased life expectancy in Canada has been accompanied by a considerable improvement in living conditions in general, Canadian realities reinforce the need for respecting diversity when developing and implementing local health policies and interventions. For a nation that is proud of its cultural mosaic, the full respect of the diversity of its elderly population and inclusion has yet to be seen.

As aging populations worldwide are faced by a relative lack of policies that consider their social, economic, behavioral and cultural aspects, interprofessional care has to be sensitive to such differences and diversity. People experience aging differently and services should be sensitive enough to take into account these differences.Nurses in particular must work interprofessionally while respecting the diversity of clientele in terms of gender, ethnicity, culture, housing, education level, marital status, living arrangements, sexual orientation, and religion.

In terms of future research studies in both countries, cross-cultural influences and interprofessional care should move hand-in-hand within and between the two nations to unravel the effects of sexuality, ethnicity, aboriginal status and gender on health care and social services' delivery.

\section{ACKNOWLEDGEMENTS}

We would like to thank Clare Davies for her feedback on the style of the manuscript and the Canadian Government/Department of Foreign Affairs and International Trade for the scholarship awarded to the first author.
IPEA; 2004

6. Canadian Institute for Health Information. Health Indicators 2010. Otawa: CIHI; 2010.

7. Statistics Canada. A portrait of seniors in Canada [Internet]. 2006 [cited 2010 May 29]. Available at: http:// www.statcan.gc.ca/ads-annonces/89-519-x/indexeng.htm.

8. Camarano AA, organizers. The new brazilian elderly: beyond the 60? Rio de Janeiro: IPEA; 2004.

9. MacArthur R. Fluctuations of animal populations and a measure of community stability. Ecology. 1995; 35: 533-6.

10. Almeida NF. The theoretical problem of the social determinants of health. Health Debate. 2009; 33: 349-70.

11. Statistics Canada. Ethnic diversity survey: portrait of a multicultural society . Ottawa: Minister of Industry; 2003. (Catalogue no. 89-593-XIE).

12. Rother ET. Revisão sistemática $X$ revisão narrative 
[editorial]. Acta Paul Enferm. 2007; 20(2): v-vi.

13. Lynam MJ. Health as a socially mediated process: theoretical and practice imperatives emerging from research on health inequalities. ANS Adv Nurs Sci. 2005; 28(1):2537.

14. Health Canada. Health Care System. Canada's Health Care System (Medicare). 2010 [cited 2010 Nov 3]. Available at: http://www.hc-sc.gc.ca/hcs-sss/medi-assur/indexeng.php.

15. Chappell N, Lynn MAcDonal, Stones M. Aging in contemporary Canada. 2nd ed. Toronto: Pearson Prentice Hall; 2008.

16. Brasil. Ministério da Saúde. Saúde Brasil 2009: uma análise da situação de saúde e da agenda nacional e internacional de prioridades em saúde. Brasília: Ministério da Saúde; 2009 [citado 2010 Nov 5] Disponível em:http:// portal.saude.gov.br/portal/arquivos/pdf/ SAUDE_BRASIL_2009_COLETIVA.pdf.

17. Statistics Canada. Canadian demographics at a glance [Internet]. 2008 [cited 2011 Sept 15] . . Ottawa: Minister; 2008 [cited 2010 Oct 13] (Catalogue 91-003-X). Available at: www.statcan.gc.ca/pub/91-003-x/91-003-x2007001eng.pdf

18. Brasil. Ministério da Saúde. Fundação Nacional da SaúdeBrazil. FUNASA - National Health Foundation. Brasília; 2009. (retrived 30, nov 2010). Available at: http:/ / www.funasa.gov.br/internet/desai / sistemaSiasiDemografiaIndigena.asp

19. Health Canada. First nations, inuit \& aboriginal health [Internet]. 2010 [cited 2010 Dec 03]. Available at: http:// www.hc-sc.gc.ca/fniah-spnia/index-eng.php

20. Anand SS, Yusuf S, Jacobs R, Davis AD, Yi Q, Gerstein $\mathrm{H}$, et al. Risk factors, atherosclerosis, and cardiovascular disease among Aboriginal people in Canada: the Study of
Health Assessment and Risk Evaluation in Aboriginal Peoples (SHARE-AP).Lancet. 2001; 358 (9288): 1147-53.

21. Camarano AA, Pasinato MT. Population aging in the public policy agenda. In: Camarano AA, organizador. The new brazilian elderly: beyond the 60? Rio de Janeiro: IPEA; 2004. p. 253-92.

22. Caldwell C. Seniors: out of the closet, into the system [Internet]. 2009. Montreal (QC): The Mcgill Daily; 2009. (cited 2010 May 29]. Available from: http:// mcgilldaily.com/articles/17824

23. Brotman S, Ryan B, Meyer E. The health and social service needs of gay and lesbian seniors and their families in Canada. Montreal: McGill School of Social Work; 2006.

24. Brotman S, Ryan B, Collins S, Collins S, Chamberland L, Cormier R, et al. Coming out to care: caregivers of gay and lesbian seniors in Canada. Gerontologist. 2007; 47 (4): 490-503.

25. Paiva V, Aranha F, Bastos FI. Opinions and attitudes regarding sexuality: brazilian national research, 2005. Rev Saúde Pública. 2008; 42 (Supl 1):54-64.

26. Arán M, Murta D, Lionço T. Transexualidade e saúde pública no Brasil. Ciênc Saúde Coletiva. 2009; 14(4):11419.

27. Ramos LR. Fatores determinantes do envelhecimento saudável em idosos residents em centro urbano: Projeto Epidoso, São Paulo.. Cad Saúde Pública. 2003; 19 (3):7938.

28. Coelho Filho JM, Ramos LR. Epidemiologia do envelhecimento no nordeste do Brasil: resultados de inquérito domiciliar. Rev Saúde Pública. 1999; 33 (5): 44553.

29. Statistics Canada. Seniors [Internet]. 2009 [cited 2010 May 29]. Available from: http:/ /www41.statcan.gc.ca/2009/ 70000/cybac70000_000-eng.htm 